\title{
Innovative Practices in Modes of College Teacher Training ZhaohongLiu $^{1, a}$, ChuanjiangYang ${ }^{1, b}$ and Shiping Liu ${ }^{1, c}$ \\ ${ }^{1}$ Chengdu Neusoft University, Chengdu, Sichuang, China, Zip Code: 611844 \\ aliuzhaohong@nsu.edu.cn, byangchuanjiang@nsu.edu.cn, c liushiping@nsu.edu.cn
}

\section{Keywords: Innovation; Project; Training mode; Five-step teaching method}

\begin{abstract}
Teachers are the main body and key of education, and the innovative practice of teacher training mode has important theoretical and practical significance. We should take the project as the main thread, also innovate and practice the five-step teaching method training mode. The five links, including pre-class communication, presenting and analyzing problems, imitating for application, discussion in the project team and studying for the purpose of application, run in a closed circle circularly, resulting in good training effects.
\end{abstract}

\section{Introduction}

Teachers are the main body and key of education. The competencies of teachers determine teaching quality and school characteristics. It affects the skills and occupational quality of the workforce and even affects the economic development and competitive strength of science and technology of the whole country. In order to fully enhance the professional skills and practical ability of secondary vocational teachers in Chengdu, a large number of leading teachers were selected by Education Department of Sichuan Province to continue education and training in colleges and universities in Sichuan. Chengdu Neusoft University undertook the training task of Java technology for teachers. In the process of training, it adheres to the combination of theory and practice along with the main thread of the project. Five-step teaching methods, including pre-class communication, presenting and analyzing problems, imitating for application, discussion in project teams and studying for the purpose of application, were used in the training process, which has a good teaching effect and receives good feedback from teachers.

\section{Training Design}

The goal of teacher training is the foundation of teacher training, and it is also an important indicator to evaluate the effect of teacher training ${ }^{[1] .}$ The trainees of this program are all graduated from computer science or related majors. For full-time computer teachers who have been working for a couple of years, it is not enough just to master the Java language. It is important for them is to achieve the training objectives of trainees with the ability to lead student teams for project development

In order to achieve the goal of training, it is essential to choose the appropriate project that students are interested in. The core topics of the project should follow the following principles, it not only bases on training content but also conforms to the cognitive level of the students and focuses on the combination of training with solving of realistic problems. Therefore, it will make it easy for students to apply the knowledge and skills they learned and cultivate their creative thinking. This requires a certain degree of difficulty so as to encourage students to study and apply new knowledge and skills. Through the communications with students, the task of project progress is jointly determined. The task is the development of the subsystem of teaching management system (usually including student management, exam management, achievement management, teacher management, course management, course selection management). As the project is closely linked with the actual work of the students, it not only make trainees to be more familiar with the system, but more importantly, the trainees' needs for the system are relatively clear. The content of educating design adopts modular structure. The structure knowledge system includes basic module, application module and the project module. Teaching requirements are organized by understanding, 
application and integrated application.

\section{Management System Design}

In order to meet the needs of project development, it introduces the management system that is similar to management of companies. Therefore, students are the main body (acting as learners, developers and managers for the project) and it forms a teacher-supervised teaching organization team. It will combine the daily management of students with teaching integration together, which provides organizational guarantees for the implementation of training. During the first training, the trainer introduces the management method for the project team and clarifies the rules and responsibilities for selection of project managers and selection methods of team members. After class, the project manager chooses members within three days. As a direct leader of all members, on the one hand, project manager exchanges and communicates with each member, formulates the project plan and implements the project development. On the other hand, the manager also takes responsibility of the trainers and reports the progress of the project on a daily basis. The project manager gets the absolute power to assess or expel members.

\section{Training Method Design}

In the process of organization and implementation of training, we should pay close attention to the innovation of training methods, and organize more interaction between the teachers and trainees in the form of workshops ${ }^{[2]}$. Five-step teaching method of training is emphasizing the participation of students and its primary purpose is to make learners in a real background of problems and generate learning needs. Through the competition among learners, teachers' instruction and the exchange and cooperation among project team members, learners can experience the whole process from identifying goals to proposing and reaching goals.

Pre-class communication is done mainly through competitions between project teams. For example, two programs are selected from the student projects. One is a representative error procedure, with error correction as the unit of the project team, and the other one is the project of higher quality and complete function and it is showed to the whole class. Another example is the interesting case of applying their knowledge to the project. By changing the passive examination to active competition and communication, the students can easily form a progress atmosphere of learning, comparing and helping with each other.

Raising and analyzing questions means that teachers provide practical questions that is beneficial to Java language teaching for students, based on the training content and actual project requirements, such as student achievement analysis, weight problems, Internet charges, and so on. These problems stemming from actual projects can lower the threshold for learning new knowledge and stimulate interest in learning so that students can clearly understand what they should do in the training. Then teachers tell students how to do in the training. It mainly formulates solutions by demonstrations, guiding students to debug procedures, explaining steps and other steps. Due to the interestingness and practicability of the raised questions, students' interest in learning can be stimulated. On the other hand, the knowledge chain has been formed through the continuity of the development projects and the connection of multiple knowledge points.

It is less difficult to imitate the content. The study is closely related to the problem of demonstration, with a slight difference. Most students can quickly code and debug them. This can greatly mobilize the enthusiasm and enhance self-confidence of students. Imitation study allows the project team to program collectively. The top three teams can receive extra points, which is contained in the project results. Most of the tasks of imitation are got from the function modules of educational administration system, and students can assemble a complete system through gradual improvement.

Project team discussion refers that students and teachers discuss and communicate with each other for some complex issues and a brief summary of knowledge. Teachers should encourage members of project teams to discuss with each other. 
Learning for practice refers that it emphasizes the use of learning and using a teacher-led ${ }^{[3]}$ and student-centered model, taken application as a purpose and a starting point. In the course of training, it increases the step of learning to apply, that is, students are required to collect and solve meaningful realistic problems in various ways. For example, after completing the control of the program flow, the teachers will ask the students to look for the actual problems around them and write the matching program to solve the problems.

\section{Assessment and Evaluation}

In order to reflect the fairness and rationality of appraisal, the program of formative appraisal that is suitable for the training of vocational teacher is finally selected from many sets of programs by the multidisciplinary of the appraisal method. The student score is calculated based on the following formula. Total grade $=$ average student performance $(10 \%)+$ team performance $(10 \%)+$ project achievement $(60 \%)+$ attendance test $(20 \%)$. Student performance is usually based on students' homework completion and attendance. The computer examination is used to assess the individual skills of Java technology. Project results show the student's team performance. Because it increases performance evaluation of members in the project, project assessment also reflects the assessment of personal ability.

\section{Conclusion}

Through innovate practices of five-step teaching method of training, training quality and efficiency greatly are improved. With the joint efforts of teachers and students, all participates reach the standard in the evaluation. The students evaluate teachers' professional level, arrangement of teaching contents, adoption of teaching methods, teaching control ability, sense of responsibility, patience and overall impression of teachers and so on. Training satisfaction reaches up to $100 \%$.

\section{References}

[1] G.Yang, C.M. Zhang: Analysis of Strengthening the Effectiveness of Teacher Training in Colleges and Universities [J]. Journal of Changchun University, 2012, (12).

[2] C. Liu: Reflections on the Training of Teachers in Colleges and Universities in the New Period [J]. Research on Teachers in Chinese Colleges and Universities, 2011, (5).

[3] Y. Qi: Curriculum Practice Based on Project Training [M]. Vocational and Technical Education, 2006, (11). 